\title{
Why do women consult doctors? Social factors and the use of the general practitioner
}

\author{
S. A. A. BERESFORD, J. J. WALlER, M. H. BANKS, AND C. J. WALE
}

From the Department of Community Medicine, St Thomas's Hospital Medical School, London SE1

SUMMARY This study was designed to investigate personal and social factors associated with demand for care by women aged between 20 and 44 years, a group unlikely to suffer from chronic illness. A random sample of women was drawn from the age-sex register of a south London group practice, and information was obtained concerning their daily symptom perception, anxiety level, social and health characteristics, and their consultations for one year. Social class, family involvement, number of children in household, satisfaction with the housing, and use of other health and social services were not associated with demand for general practitioner care. Absence of basic housing amenities, difficulties in running the household, brevity of stay in the house or neighbourhood, and lack of attachment to the neighbourhood were related to a high patient-initiated consultation rate. Some of the possible interpretations of these results are discussed together with their implications for social policy planning.

In Britain there are no obvious financial constraints influencing an individual's decision to seek medical care from his or her general practitioner. Nevertheless there is great variation from individual to individual on the frequency with which such demands are made. Many studies have shown that such variation depends partly on susceptibility to disease, partly on demographic characteristicssuch as, age, sex (Logan and Cushion, 1958; Office of Population Censuses and Surveys, 1974), marital state (Ashford and Pearson, 1970), education (Ashford and Pearson, 1970; Rahe et al., 1970; Waller and Morrell, 1972), and occupation (Logan and Cushion, 1958; Kedward, 1962; Scott and McVie, 1962) -and partly on other personal, social, and cultural factors (Mechanic, 1962; Hull, 1969; Morrell, 1972; Rea, 1972 personal communication). There is also some indication that the doctor himself can influence the use of his services (Balint, 1964), but we have limited ourselves to examining some characteristics of those seeking medical care.

This paper reports on the association between demand for general practitioner care, as measured by patient-initiated consultation rate, and certain social and environmental factors. An earlier paper (Banks et al., 1975) described the aims of the study, its design, and the associations between anxiety, perception of symptoms, and demand for primary care.

\section{Method}

A random sample of 516 women aged between 20 and 44 years was drawn from the age-sex registe of the Lambeth Road group practice. These womes were selected because they were unlikely to suffe? from acute diseases of childhood or chronic degenerative diseases and yet had a high level of demand for medical care (Morrell et al., 1970). Of these, the Executive Council had only 415 registered with the practice on the date the study began. One hundred and forty-three (34\%) of them moved house or left the practice before a fieldworker visited them and nine $(2 \%)$ were excluded because of various personal or family difficulties. Therefore, 263 women were contacted of whom six $(2 \%)$ left the practice before the end of the study year, and $39(15 \%)$ failed to co-operate. Two hundred and eighteen (82\%) of the contacts completed the interview and were registered with the practice throughout the study year (Table 1).

Each subject was interviewed in her home by the fieldworker and completed a structured questionnaire on social conditions and a second questionnaire designed to measure anxiety level (Cattell and Scheier, 1963); each woman kept a health diary in which she recorded symptoms and self medication for four weeks, and a special record was kept at the practice of her consultations for a period of one year (the study year). 
Table 1 Contacts and participants

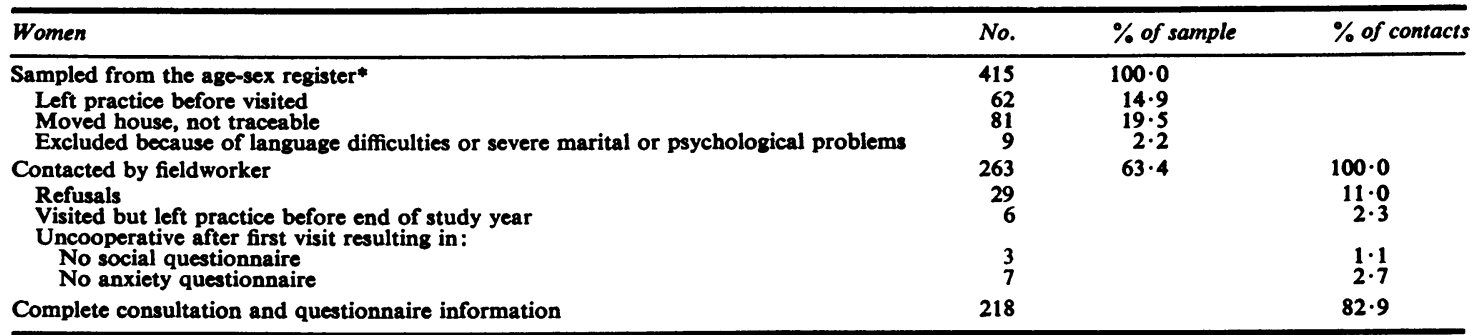

-Included after checks with Executive Council records

The annual number of patient-initiated consultations which formed the measure of demand for medical care followed a Poisson distribution with a mean of 1.86 consultations. This was transformed by equation 1 to a variable $y$ which was approximately Normal, thus permitting standard errors of the mean and analysis of variance to be used.

$$
\mathbf{y}=\sqrt{\mathbf{R}}+\sqrt{\mathbf{R}+1} \quad \ldots \text { Equation } 1
$$

where $R$ is the number of patient-initiated consultations.

\section{Results}

The 218 women for whom complete information was available by way of consultations and questionnaires were fairly evenly distributed among the ages 20 to 44, with a slight excess in the 25 to 29 year age group. Fifty-eight per cent were married, $20 \%$ single, and the remaining $11 \%$ were widowed, divorced, or separated. Just over half the women were classified as social class III and about onequarter were social class I or II. Over two-thirds of the women had some kind of paid job of their own. Eleven per cent of the women lived on their own, $15 \%$ had a household size of two, $30 \%$ had three, while $22 \%$ had at least five in the household. The majority $(83 \%)$ lived in a flat, and $18 \%$ of flatdwellers were on the fourth floor or higher. In the older residences in Lambeth the basic facilities are of a low standard: $16 \%$ of our study group had no access to a bathroom or a fixed bath, $4 \%$ had no access to an indoor lavatory, and $2 \%$ had no kitchen facilities. Parents and parents-in-law tended to live nearby, and $48 \%$ of the women in the study saw one or other parent at least once a week.

Although the average consultation rates were similar for single, married and widowed, divorced or separated women (1.86 patient-initiated consultations a year), the relationship between the social characteristics and frequency of demand for care was often different for each group of marital state. In particular, the association between a social factor and demand was in a different direction for the widowed, divorced, or separated women from that of the married or single women. The analyses were therefore performed separately for each marital state, although results for the single and married groups were combined if the associations were sufficiently similar.

The social characteristics could be divided into five areas: socioeconomic status, alternative forms of support, environment, housing, and household.

None of the factors-social class, age at leaving school, or work status-was significantly associated with demand, although the married women who had had no further education consulted more frequently than those who had had some further education $(P<0.1)$ (Table 2). This result is similar to that of an earlier study (Waller and Morrell, 1972) in which mothers who had had no further education were found to consult more frequently on behalf of their child for symptoms of the common cold, even after controlling for social class.

Other studies (Cartwright and Jefferys, 1958; Geersten and Gray, 1970) showed that women who had heavy responsibilities at work or with their children were less inclined to adopt the sick role than others. In our study the association between consultations and reported ease in obtaining time off work or child-minding was found only for the married group $(P<0.05)$. In contrast the single women who found it easy to obtain time off work consulted significantly less often $(P<0.05)$ (Table 3).

A measure of the importance of family and close relatives in the life of the individual was developed as a 16-item scale by Bardis (1959) and modified by Geersten and Gray (1970). A high 'familism' score on this scale means that the family takes precedence over the individual, that each individual should place family interests above his own, and 
Table 2 Further education by transformed consultation rate

\begin{tabular}{|c|c|c|c|c|}
\hline \multirow[b]{2}{*}{ Marital state } & & \multicolumn{3}{|c|}{ Further education } \\
\hline & & None & Some & \\
\hline Single & $\begin{array}{l}\text { Mean transformed rate } \pm \text { SE } \\
\text { Equivalent consultation rate } \\
\text { No. of women in group }\end{array}$ & $\begin{array}{l}2 \cdot 98 \pm 0.26 \\
1 \cdot 75 \\
33\end{array}$ & $\begin{array}{l}3 \cdot 04 \pm 0 \cdot 25 \\
1 \cdot 84 \\
33\end{array}$ & NS \\
\hline Married & $\begin{array}{l}\text { Mean transformed rate } \pm S E \\
\text { Equivalent consultation rate } \\
\text { No. of women in group }\end{array}$ & $\begin{array}{l}3 \cdot 21 \pm 0 \cdot 15 \\
2 \cdot 10 \\
94\end{array}$ & $\begin{array}{l}2 \cdot 70 \pm 0 \cdot 24 \\
1 \cdot 36 \\
33\end{array}$ & + \\
\hline Widowed, divorced, or separated & $\begin{array}{l}\text { Mean transformed rate } \pm S E \\
\text { Equivalent consultation rate } \\
\text { No. of women in group }\end{array}$ & $\begin{array}{l}3 \cdot 30 \pm 0 \cdot 39 \\
2 \cdot 25 \\
18\end{array}$ & $\begin{array}{l}2 \cdot 56 \pm 0.63 \\
1 \cdot 18\end{array}$ & NS \\
\hline
\end{tabular}

Note: If $\bar{y}$ is the mean transformed rate, equivalent consultation rate $=\left(\frac{\bar{y}^{2}-1}{2 \bar{y}}\right)^{2}$

Key: $+\mathbf{P}<0 \cdot 10 ;$ NS non-significant $(P>0 \cdot 10)$

Table 3 Ease in obtaining time off work or child-minding by transformed consultation rate

\begin{tabular}{|c|c|c|c|c|c|}
\hline Marital state & & Very easy & Fairly easy & Neutral or difficult & \\
\hline Single & $\begin{array}{l}\text { Mean transformed rate } \pm \text { SE } \\
\text { Equivalent consultation rate } \\
\text { No. of women in group }\end{array}$ & $\begin{array}{l}2 \cdot 42 \pm 0.34 \\
1 \cdot 01 \\
17\end{array}$ & $\begin{array}{l}2 \cdot 86 \pm 0 \cdot 31 \\
1 \cdot 58 \\
17\end{array}$ & $\begin{array}{l}3 \cdot 46 \pm 0 \cdot 28 \\
2 \cdot 51 \\
25\end{array}$ & $*$ \\
\hline Married & $\begin{array}{l}\text { Mean transformed rate } \pm S E \\
\text { Equivalent consultation rate } \\
\text { No. of women in group }\end{array}$ & $\begin{array}{l}3 \cdot 50 \pm 0 \cdot 23 \\
2 \cdot 58 \\
38\end{array}$ & $\begin{array}{l}2 \cdot 92 \\
1 \cdot 66 \\
44\end{array}$ & $\begin{array}{l}2 \cdot 93 \\
1.68 \\
41\end{array}$ & $*$ \\
\hline Widowed, divorced, or separated & $\begin{array}{l}\text { Mean transformed rate } \pm \text { SE } \\
\text { Equivalent consultation rate } \\
\text { No. of women in group }\end{array}$ & $\begin{array}{l}2 \cdot 79 \\
1 \cdot 48 \\
8\end{array}$ & $\begin{array}{l}2 \cdot 94 \\
1 \cdot 69 \\
3\end{array}$ & $\begin{array}{l}3 \cdot 68 \pm 0.43 \\
2.90 \\
12\end{array}$ & 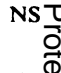 \\
\hline
\end{tabular}

that family members both immediate and extended are expected to provide assistance at times of need. In contrast to Geersten and Gray (1970) we found that those women with a low 'familism' score were just as likely to consult the doctor as those with a high score, and even when we confined the analysis to mothers, we still found no difference.

Support from the family, neighbours, and even district nurses or health visitors may obviate the necessity for a visit to the doctor, and so we also inquired about the family and other people in the neighbourhood. Although nearly half the women saw their mother more frequently than once a week, and one in three of the mothers lived in Lambeth, neither proximity of family nor frequency of contact with family was associated with consultation rate.

We compared the consultation rates of those who said they talked to someone (for example, husband or mother) when they felt unwell, with those who kept such information to themselves. They did not differ significantly. Contact with a health visitor, district nurse, practice nurse, or social worker during the previous two weeks did not appear to influence the rate of consultation with the doctor, except that among the women who were not now married, those who had seen a social worker had a lower consultation rate $(P<0 \cdot 1)$.
Various factors relating to the neighbourhood were examined. An indication of adaption to city. life is given by the number of years a woman has lived in some part of London. Combining the single and married groups, those women who had lived in London for at least 10 years consulted less frequently than those who had lived in London for less than 10 years $(P<0.05)$. The association was less strong $(P<0.1)$ after adjusting for age. In the same way, single and married women who had lived in the neighbourhood for at least three years consulted on fewer occasions than those who had lived there for only one or two years $(P<0.05)$. The difference was reduced $(P<0.1)$ after adjusting for age. In contrast the widowed, divorced, or separated women consulted more often the longer they had been living in the area (Table 4). The linear relationship between the transformed consultation rate and the number of years lived in the neighbourhood was significant at the $1 \% \frac{7}{O}$ level for the widowed, divorced, or separated group. The level of significance was not reduced when $N$ anxiety level, age, and attachment to the neighbourhood were taken into account.

The degree of attachment to the neighbourhood was measured using a series of five-point Lickert scales*. The replies were significantly associated 0 *These were designed with the help of Dr C. Nathanson 
Table 4 Length of time lived in Lambeth or Southwark by transformed consultation rate

\begin{tabular}{|c|c|c|c|c|c|c|}
\hline \multirow[b]{2}{*}{ Marital state } & & \multicolumn{5}{|l|}{ Years } \\
\hline & & Up to 2 & $3-9$ & $10-20$ & Over 20 & \\
\hline Single and married & $\begin{array}{l}\text { Mean transformed rate } \pm S E \\
\text { Equivalent consultation rate } \\
\text { No. of women in group }\end{array}$ & $\begin{array}{l}3 \cdot 57 \pm 0 \cdot 25 \\
2 \cdot 71 \\
34\end{array}$ & $\begin{array}{l}2 \cdot 95 \pm 0 \cdot 15 \\
1 \cdot 70\end{array}$ & $\begin{array}{l}2 \cdot 73 \pm 0 \cdot 22 \\
1 \cdot 40 \\
34\end{array}$ & $\begin{array}{l}3 \cdot 07 \pm 0 \cdot 22 \\
1 \cdot 88 \\
54\end{array}$ & * \\
\hline Widowed, divorced, or separated & $\begin{array}{l}\text { Mean transformed rate } \pm S E \\
\text { Equivalent consultation rate } \\
\text { No. of women in group }\end{array}$ & $\begin{array}{l}1.81 \pm 0.81 \\
0.40 \\
4\end{array}$ & $\begin{array}{l}2.75 \\
1.42\end{array} \pm 0.42$ & $\begin{array}{l}3 \cdot 48 \\
2 \cdot 55 \\
8\end{array}$ & $\begin{array}{l}4 \cdot 42 \pm 0 \cdot 88 \\
4 \cdot 40 \\
5\end{array}$ & ** \\
\hline
\end{tabular}

Note: If $\bar{y}$ is the mean transformed rate, equivalent consultation rate $=\left(\frac{\bar{y}^{2}-1}{2 \bar{y}}\right)^{2}$

Key: ** $P<0.01 ; * P<0.05$

Table 5 Attachment to neighbourhood by transformed consultation rate

\begin{tabular}{|c|c|c|c|c|c|}
\hline \multirow[b]{2}{*}{ Marital state } & & \multicolumn{4}{|l|}{ Score } \\
\hline & & $1-$ & $2 \cdot 5-$ & $3 \cdot 5-5$ & \\
\hline Single and married & $\begin{array}{l}\text { Mean transformed rate } \pm S E \\
\text { Equivalent consultation rate } \\
\text { No. of women in group }\end{array}$ & $\begin{array}{l}2 \cdot 72 \pm 0 \cdot 20 \\
1 \cdot 38 \\
44\end{array}$ & $\begin{array}{l}3 \cdot 15 \pm 0 \cdot 13 \\
2 \cdot 01 \\
122\end{array}$ & $\begin{array}{l}3 \cdot 18 \pm 0 \cdot 32 \\
2 \cdot 05 \\
23\end{array}$ & $\bullet$ \\
\hline Widowed, divorced, or separated & $\begin{array}{l}\text { Mean transformed rate } \pm S E \\
\text { Equivalent consultation rate } \\
\text { No. of women in group }\end{array}$ & $\begin{array}{l}3 \cdot 19 \pm 0 \cdot 92 \\
2 \cdot 07 \\
4\end{array}$ & $\begin{array}{l}2.92 \\
1.66 \\
16\end{array}$ & $\begin{array}{l}3 \cdot 57 \pm 0 \cdot 92 \\
2 \cdot 71 \\
5\end{array}$ & NS \\
\hline
\end{tabular}

Note: If $\bar{y}$ is the mean transformed rate, equivalent consultation rate $=\left(\frac{\bar{y}^{2}-1}{2 \bar{y}}\right)^{2}$

Key: * $P<0.05$; NS non-significant

with demand for care by single and married women $(P<0.05)$. Those women who were attached to the neighbourhood consulted less often than those who were not (Table 5).

Housing characteristics were the next social factors to be examined. No association was found between demand and certain living conditions: whether the respondent lived in a family house or a flat, the floor the flat was on, the number of people per room, the bedroom crowding, the satisfaction with the housing, or the attachment to the housing. However those single or married women who had been living in their house or flat for three years did consult less often than those who had been in their home only for a short time $(P<0.05)$. The difference was reduced $(P<0 \cdot 10)$ after adjusting for age.

There were not many women in the study who were without one of the basic housing amenities of kitchen, own indoor lavatory, and own fixed bath. The women were given a score from 0 to 3 according to the number of amenities they had. For the married group, the greater the number of amenities, the lower was the consultation rate $(P<0.05)$. The relationship persisted independent of age and anxiety level. No married woman was without all three amenities. This association was not found for the single women. However, when we constructed a similar score for bedroom facilities: privacy, not disturbed by noise, and not sharing the bedroom with a child, we found that those single women with at least two facilities consulted significantly less frequently than those who had only one of these bedroom facilities $(P<0.05)$. Again the relationship persisted after adjusting for age and anxiety, but this time no association was found for the married group (Tables 6a, b).

Some aspects of the household were investigated such as size of the household, and the number of children, but neither of these was associated with demand for care by the single or married group. A small association between the size of household and consultation rate was discovered in the widowed, divorced, or separated group $(P<0 \cdot 1)$ : the larger the household, the greater the number of consultations. Those women who said they were in charge of running the household were asked how easy or difficult they found it. Those who admitted to finding it difficult, or very difficult, had significantly more consultations, taking all three groups of marital state together $(P<0.05)$ (Table 7).

\section{Discussion}

The high mobility of the patients registered with the Lambeth Road group practice is typical of southeast London where a large amount of rebuilding is taking place. The women who remained registered with the practice for the entire year therefore represented the more residentially stable members of the neighbourhood. Our finding that the widowed, divorced, or separated women generally did not consult more frequently than 
Table 6a Number of housing amenities (kitchen, indoor lavatory, fixed bath) by transformed consultation rate

\begin{tabular}{|c|c|c|c|c|c|}
\hline Marital state & & None & One & Two & Three \\
\hline Single & $\begin{array}{l}\text { Mean transformed rate } \pm S E \\
\text { Equivalent consultation rate } \\
\text { No. of women in group }\end{array}$ & $\begin{array}{l}3.61 \\
2.78 \\
3\end{array}$ & $\begin{array}{l}2 \cdot 28 \\
0.85 \\
12\end{array}$ & $\begin{array}{l}3 \cdot 89 \\
3 \cdot 30 \\
6\end{array}$ & $\begin{array}{l}3.09 \pm 0.21 \\
1.91 \\
44\end{array}$ \\
\hline Married & $\begin{array}{l}\text { Mean transformed rate } \pm S E \\
\text { Equivalent consultation rate } \\
\text { No. of women in group }\end{array}$ & $\overline{0}$ & $\begin{array}{l}3 \cdot 76 \pm 0.49 \\
3 \cdot 05 \\
12\end{array}$ & $\begin{array}{l}3 \cdot 43 \pm 0.39 \\
2 \cdot 46 \\
14\end{array}$ & $\begin{array}{l}2.96 \\
1.72 \\
99\end{array}$ \\
\hline Widowed, divorced, or separated & $\begin{array}{l}\text { Mean transformed rate } \pm S E \\
\text { Equivalent consultation rate } \\
\text { No. of women in group }\end{array}$ & $\begin{array}{l}2 \cdot 41 \pm- \\
1.00 \\
1\end{array}$ & $\begin{array}{l}4 \cdot 49 \pm 1 \cdot 34 \\
4 \cdot 55 \\
2\end{array}$ & $\begin{array}{l}2 \cdot 41 \\
1 \cdot 00 \\
2\end{array}$ & $\begin{array}{l}3.17 \pm 0.39 \\
2.04 \\
19\end{array}$ \\
\hline
\end{tabular}

Note: If $\bar{y}$ is the mean transformed rate, equivalent consultation rate $=\left(\frac{\bar{y}^{2}-1}{2 \bar{y}}\right)^{2}$

Key: * $P<0.05$; NS non-significant

Table 6b Number of bedroom facilities (privacy, not disturbed by noise, not sharing with a child) by transformed $\dot{\vec{\omega}}$ consultation rate

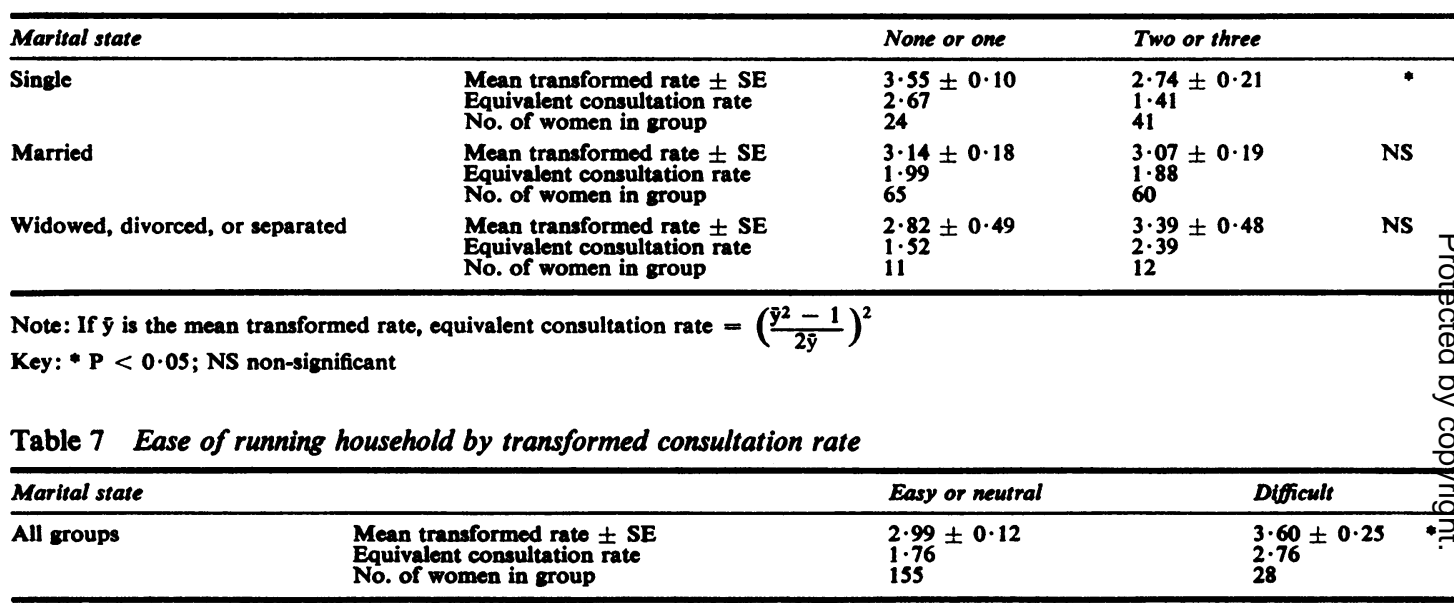

Note: If $\bar{y}$ is the mean transformed rate, equivalent consultation rate $=\left(\frac{\bar{y}^{2}-1}{2 \bar{y}}\right)^{2}$

Key: $* P<0.05$

NB Those women who were not in charge of running the household have been excluded

either the single or the married women is in contrast to the patients in the age group 20 to 49 in the Exeter study (Ashford and Pearson, 1970), where the widowed and divorced had higher consultation rates than the married, who had higher rates than the single. The difference in results of the two studies may be a reflection of the differences between Exeter and Lambeth, or it may be owing to the fact that men as well as women were studied in Exeter and consultation rates were combined.

The way in which the association between many of the social factors and demand for care differs for the not now married group from the single or married groups is of interest although it is difficult to interpret. In particular, the very strong positive association between the length of time lived in Lambeth or Southwark and consultation rate for the widowed, divorced, or separated women is contrary to expectation. One may speculate that for these women a short time in the neighbourhood may imply a new environment since the demise of the marriage, while those who have lived there for $\mathbb{D}$ longer may have to contend with the stress of? painful memories.

It is often suggested (for example, Fanning, 1967) that living in a flat is a source of stress and isolation, especially if the flat is in a multistorey block. However no measurable effect was detected 윽 in the consultation rates of women in this study, $D$ possibly because so many of them live in flats and they have come to accept this as normal, or $N$ perhaps because many of the blocks of fiats are built with balconies around a common courtyard, $N$ so that contact with the neighbours is easy. Neither $\mathrm{W}$ overcrowding in the home nor number of persons? per bedroom had any measurable association witho demand for medical care although $23 \%$ were $\overparen{\Phi}$ 
overcrowded according to the General Household Survey criterion.

In view of earlier research it is surprising that not more of the measures of social factors showed significant results, particularly the alternative support network which might prevent demand for care from the general practitioner. There is some indication from our data that highly anxious women do consult less frequently if they discuss their health with their husband or mother, while less anxious women demand support from more than one agent, and so lean on the family as well as on the general practitioner. Another study of this same practice (Waller and Morrell, 1972), showed that mothers who consulted the doctor about their children were more likely also to be attending an infant welfare clinic. If this mechanism applied to those women in our study with medium or low anxiety, while highly anxious women talked to someone other than the doctor and thus reduced the need for a consultation, then the whole group would show an overall lack of association between demand for primary medical care and use of alternative support.

The study group may be too small for a weak relationship between a social factor and demand for medical care to reach statistical significance. For example, with sample sizes of between 750 and 950, Hall (1976) was able to demonstrate relationships between hard measures and subjective survey responses to questions such as those relating to housing satisfaction, housing nuisance, and satisfaction with local district. Alternatively it may be that the measurement tool is not refined enough to detect the small differences in attitude which may lead to differing demands for care. The patient-initiated consultations have been treated in a static way, by using the total demand for the whole year: any transient effect of social attitudes would therefore be missed.

\section{Conclusion}

For single and currently married women the home is important in differentiating between high and low users of care. Women who have poor housing amenities, inadequate bedroom facilities, have lived in their home for a comparatively short time, and who find the household difficult to run do initiate a consultation with the doctor more frequently than do the rest.

It is known that new towns generally have high rates of demand for medical care during their first few years. An established area with a lot of rebuilding and migration may have consultation patterns similar to those of a new town. This is not borne out in Croydon, where Hare and Shaw (1965) found no difference in sickness between old and new wards. However we have shown in Lambeth that those women who have lived in the area for a longer time, who are attached to the neighbourhood, and are used to the stresses of city life do consult less than the others.

If the association is causal, it may be that women with high levels of demand for medical care move house more often, or conversely it may be that women more attached to the neighbourhood are less stressed and so consult less. Should the latter prove true, support ought to be given to those who plan community involvement to foster greater neighbourhood attachment. This should reduce the need for general practitioner care and lead to a reduction in demand of the medical care system.

We should like to thank the patients and doctors of the Lambeth Road group practice, Professor D. C. Morrell, Miss M. Goulding, Dr M. Griffin, Miss N. Salmon, Mrs A. Jacoby and Miss P. Thomas, and the University of London Computing Centre. This work was supported in part by a grant from the Department of Health and Social Security.

Reprints from S. A. A. Beresford, Department of Clinical Epidemiology and Social Medicine, Royal Free Hospital School of Medicine, 21 Pond Street, London NW3 2PN.

\section{References}

Ashford, J. R., and Pearson, N. G. (1970). Who uses the health services and why? Journal of the Royal Statistical Society (A), 133, 295-357.

Balint, M. (1964). The Doctor, his Patient and the Illness, second edition. Pitman Medical: London.

Banks, M. H., Beresford, S. A. A., Morrell, D. C., Waller, J. J., and Watkins, C. J. (1975). Factors influencing demand for primary medical care in women. International Journal of Epidemiology, 4, 189-195.

Bardis, P. D. (1959). A familism scale. Marriage and Family Living, 21, 340-341.

Cartwright, A., and Jefferys, M. (1958). Married women who work: Their own and their children's health. British Journal of Preventive and Social Medicine, 12, 159-171.

Cattell, R. B., and Scheier, I. H. (1963). Handbook for the IPAT Scale Questionnaire. IPAT: Champagne, Illinois.

Fanning, D. M. (1967). Families in flats. British Medical Journal, 4, 382-386.

Geersten, H. R., and Gray, R. M. (1970). Familistic orientation and inclination towards adopting the sick role. Journal of Marriage and the Family, 32, 638-646. 
Hall, J. (1976). Subjective Measures of Quality of Life in Britain 1971 to 1975. Some Developments and Trends. Social Trends No. 7, pp. 47-60. Edited by E. J. Thompson. HMSO: London.

Hare, E. H., and Shaw, G. K. (1965). Mental Health on a New Housing Estate: A Comparative Study of Health in Two Districts of Croydon. Maudsley Monograph No. 12. Oxford University Press: London.

Hull, F. M. (1969). Social class consultation patterns in rural general practice. Journal of the Royal College of General Practitioners, 18, 65-71.

Kedward, H. B. (1962). Social class habits of consulting. British Journal of Preventive and Social Medicine, 16, 147-152.

Logan, W. P. D., and Cushion, A. A. (1958). Morbidity Statistics for General Practice, volume 1, GRO No. 14. HMSO: London.

Mechanic, D. (1962). The concept of illness behaviour. Journal of Chronic Diseases, 15, 189-194.

Morrell, D. C. (1972). Symptom interpretation in general practice. Journal of the Royal College of General Practitioners, 22, 297-309.
Morrell, D. C., Gage, H. G., and Robinson, N. R. (1970). Patterns of demand in general practice. Journal of the Royal College of General Practitioners, 19, 331-342.

Office of Population Censuses and Surveys (1974). Morbidity Statistics from General Practice. Studies on Medical and Population Subjects No. 26. HMSO: London.

Rahe, R. H., Gunderson, E., and Ransom, J. A. (1970). Demographic and psychosocial factors in acute illness reporting. Journal of Chronic Diseases, 23, 245-255.

Scott, R., and McVie, D. H. (1962). Doctor in the house: An analysis of house visits in a general practice. Journal of the Royal College of General Practitioners, 5, 72-85.

Waller, J. J., and Morrell, D. C. (1972). Multidisciplinary research in general practice. Paper read to scientific meeting of staff of academic departments of general practice, Cardiff. 